\title{
Os 80 Anos do Primeiro Curso de Matemática Brasileiro: sentidos possíveis de uma comemoração acerca da formação de professores no Brasil
}

\author{
The Eightieth Anniversary of the First Mathematics Undergraduate Course \\ in Brazil: possible meaning for a celebration about teacher's education
}

Maria Laura Magalhães Gomes*

\begin{abstract}
Resumo
Este artigo focaliza a passagem dos 80 anos do primeiro curso de Matemática no Brasil, o da Universidade de São Paulo (USP), no contexto dos debates sobre a formação inicial de professores no país. A abordagem é realizada em três seções que seguem uma breve introdução. A primeira contempla a implantação do curso, suas características e relações com a preparação docente para o ensino secundário. A segunda apresenta uma discussão sobre a visão da criação desse curso como um acontecimento fundador na história da formação institucional superior de professores de Matemática no Brasil. Na última parte, tecem-se considerações sobre questões atuais da formação inicial desses professores no país, buscando relações entre elas e a preparação que se propôs e se passou a realizar a partir do estabelecimento do curso da USP.
\end{abstract}

Palavras-chave: Octogésimo Aniversário do Primeiro Curso de Matemática do Brasil. Questões Atuais na Formação Inicial de Professores de Matemática.

\begin{abstract}
This article focuses on the $80^{\text {th }}$ anniversary of the first Mathematics undergraduate course in Brazil, at University of São Paulo (USP), in the context of discussions about teacher's training in the country. The text has three sections, which follow a brief introduction. The first one covers the implementation of the course, its characteristics, and relations with teacher training for secondary education. The second one presents a discussion on the vision for the creation of this course as a founding event in the history of a higher institutional training of mathematics teachers in Brazil. In the last part, we consider current issues concerning mathematics teacher's education, and try to relate them to the education that was proposed and has been offered since the course foundation at USP.
\end{abstract}

Key Words: Eightieth Anniversary of the First Mathematics Undergraduate Course in Brazil. Current Issues Concerning Mathematics Teacher's Education.

\footnotetext{
" Doutora em Educação pela Universidade Estadual de Campinas (UNICAMP). Professora do Departamento de Matemática e do Programa de Pós-Graduação em Educação da Universidade Federal de Minas Gerais (UFMG), Belo Horizonte/MG, Brasil. Bolsista de Produtividade em Pesquisa do CNPq. Endereço para correspondência: Departamento de Matemática, ICEx-UFMG, Av. Antônio Carlos, n. 6627, Cidade Universitária- Pampulha, Belo Horizonte/ MG, CEP 321270-901, Brasil. E-mail: mlauramgomes@ gmail.com.
} 


\section{Introdução}

Em 2014, comemorou-se a passagem do octogésimo aniversário do primeiro curso de Matemática no Brasil, o da Universidade de São Paulo ${ }^{1}$. Neste artigo, buscamos focalizar essa efeméride no contexto dos debates sobre a formação inicial de professores de Matemática em nosso país, por acreditarmos que a compreensão dessa complexa temática pode se beneficiar do conhecimento de seus antecedentes, contextos de surgimento, interesses e sujeitos envolvidos, bem como dos discursos a ela referentes presentes no Brasil em diferentes conjunturas históricas. Ao valorizar o estudo e as discussões sobre a trajetória da formação inicial de professores de Matemática no país, reconhecemos as contribuições do pensamento histórico, avesso à aceitação de informações e ideias alheadas da consideração sobre os cenários em que surgiram, do foco nas potencialidades e limites dos conhecimentos que circularam nos diferentes momentos da trajetória da formação inicial de professores de Matemática no país. Neste texto, a abordagem do tema é organizada em três partes, brevemente descritas a seguir.

Em primeiro lugar, procuramos contemplar o contexto de implantação do curso, aludindo a algumas de suas características e peculiaridades e referindo-me, particularmente, a suas relações com a formação inicial de docentes para o ensino secundário.

Num segundo momento, propomos uma discussão sobre a visão da criação desse curso como um acontecimento fundador na história da formação em nível superior específica para professores de Matemática no Brasil.

Por fim, tecemos considerações acerca de questões do presente da formação inicial desses docentes em nosso país, buscando conectá-las à preparação institucional que se propôs e se passou a realizar a partir do estabelecimento do curso cuja criação celebrou 80 anos.

\section{Em torno do surgimento do curso de Matemática da Universidade de São Paulo e de suas relações com a formação de professores}

Com efeito, completaram-se, em 2014, 80 anos da criação do primeiro curso de Matemática no Brasil. Embora saibamos que houve ensino de Matemática desde muito antes, na Colônia, no Império e nas primeiras décadas da República, tendo existido, portanto,

\footnotetext{
${ }^{1}$ Este artigo é uma versão modificada de conferência proferida em 12/12/2014, na abertura do V Fórum Nacional de Licenciaturas em Matemática, promovido pela Sociedade Brasileira de Educação Matemática (SBEM) e realizado na Universidade Estadual de Londrina (UEL).
} 
professores responsáveis por esse ensino em diversos níveis, o primeiro curso de Matemática estabelecido entre nós foi o da Universidade de São Paulo (USP), no ano de 1934. Essa universidade foi instituída pelo Decreto 6284 do governo estadual, de 25 de janeiro do mesmo ano, e sua criação envolveu negociações e conflitos ligados à resistência das elites paulistas ao governo federal, então sediado no Rio de Janeiro. De acordo com Cardoso (1982), a implantação da USP resultou, sobretudo, de um projeto político centrado na formação das elites intelectuais que deveriam dirigir o país.

É importante lembrar que a USP e a Universidade do Distrito Federal, estabelecida em 1935 no Rio de Janeiro, são as duas primeiras universidades criadas a partir de um dos decretos da Reforma Francisco Campos, de 1931 - o Estatuto das Universidades Brasileiras. O decreto "colocava no cerne da Universidade o problema da educação nacional, vinculando a ela, por seu instituto básico - a Faculdade de Educação, Ciências e Letras - o projeto maior da educação pública" (PENIN, 2001). É usual destacar, na exposição de motivos do documento regulador do Ensino Superior, assinada por Francisco Campos, o caráter urgente atribuído à necessidade de prover uma formação profissional para os professores, em especial os do ensino secundário. A Faculdade de Educação, Ciências e Letras prevista no Decreto ${ }^{\circ}$ 19850, de 11 de abril de 1931, deveria ser, além de um "órgão de alta cultura ou de ciência pura e desinteressada", sobretudo, um "Instituto de Educação", dotado de "todos os elementos próprios e indispensáveis a formar o nosso corpo de professores, particularmente os do ensino moral e secundário", porque deles, de modo próximo e imediato, dependeria "a possibilidade de se desenvolver, em extensão e profundidade, o organismo, ainda rudimentar, de nossa cultura". O texto criticava a cultura autodidática dos professores dominante no país e enfatizava a ideia de que faltava ao ensino secundário brasileiro um corpo docente "de orientação didática segura e com sólidos fundamentos em uma tradição de cultura, particularmente no que se refere às ciências básicas e fundamentais ${ }^{2} \%$.

$\mathrm{Na}$ concepção do Estatuto das Universidades Brasileiras, a idealizada Faculdade de Educação, Ciências e Letras tinha como sua principal função formar professores para a escola secundária e essa atribuição era considerada compatível com a produção do conhecimento e a prática da pesquisa (CACETE, 2014). Contudo, a instituição não chegou a ser implantada no país como fora prevista no documento de 1931. As instituições que surgiram foram chamadas Faculdades de Filosofia ou Faculdades de Filosofia, Ciências e Letras e, embora

\footnotetext{
2 Todas as expressões entre aspas deste parágrafo são transcritas do Decreto Lei $\mathrm{n}^{\circ} 19850$, de 11 de abril de 1931. Disponível em http://www2.camara.leg.br/legin/fed/decret/1930-1939/decreto-19850-11-abril-1931515692-publicacaooriginal-1-pe.html. Acesso em 09 dez 2014.
} 
historicamente constituídas como lugar de formação dos professores secundários no Brasil, não concretizaram a proposta da Reforma Campos, que procurava conjugar o "ideal da pesquisa científica pura em um sistema tradicionalmente profissionalizante e a introdução dos estudos pedagógicos para a formação de professores para a escola secundária em nível superior" (CACETE, 2014, p. 4).

Na USP, implementou-se, no mesmo ano de sua fundação, a Faculdade de Filosofia, Ciências e Letras ${ }^{3}$ (sem que a Educação prevista no Estatuto fizesse parte do nome ou do conjunto de seções constituintes da nova unidade universitária). Segundo Cacete (2014), essa Faculdade, interessada na integração das escolas superiores e no cultivo de estudos não profissionais, não instalou logo de início uma seção de Educação, tendo, assim, negado a formação de professores no seu escopo. Meses antes do decreto de fundação da USP, havia se criado, no Instituto de Educação de São Paulo, um curso para formar professores secundários, e esse curso foi incorporado à Universidade. A circunstância de já existir esse Instituto, como escola independente e de caráter profissionalizante, parece, de acordo com autores citados por Penin (2011), ter facilitado a concretização do projeto paulista no referente à sua tendência a eliminar da Faculdade de Filosofia todos os componentes utilitários, afastando dessa instituição os estudos da educação. O curso de formação de professores para a escola secundária do Instituto de Educação, de dois anos, foi anexado à Faculdade de Filosofia, Ciências e Letras, e somente em 1938 criou-se, nessa escola, a seção de Pedagogia.

Como se situa então, nesse contexto, a implantação do curso de Matemática? A Faculdade de Filosofia, Ciências e Letras compreendia, em sua implantação, três seções Filosofia, Ciências e Letras -, e a primeira subseção da seção de Ciências, denominada Ciências Matemáticas, se organizava, de acordo com o Decreto 7069/35, em três cadeiras: Geometria (Projetiva e Analítica) e História das Matemáticas; Análise Matemática; Mecânica Racional (PIRES, 2006; ZICCARDI, 2009). O mesmo decreto fixava a seriação do curso em três anos, nos quais assim se distribuíam as disciplinas:

$1^{\mathrm{o}}$ ano: Geometria (Analítica e Projetiva), Análise Matemática ( $1^{\mathrm{a}}$ parte), Física Geral e Experimental ( $1^{\mathrm{a}}$ parte $)$, Cálculo Vetorial;

$2^{\circ}$ ano: Análise Matemática ( $2^{\mathrm{a}}$ parte), Mecânica Racional, Física Geral e Experimental (2 ${ }^{\mathrm{a}}$ parte);

\footnotetext{
${ }^{3}$ A Universidade de São Paulo, em sua fundação, compunha-se, além da nova Faculdade de Filosofia, Ciências e Letras, da Escola Politécnica, da Faculdade de Direito, da Escola de Farmácia e Odontologia, da Escola Superior de Agronomia Luís de Queiroz, da Faculdade de Medicina e de alguns institutos de pesquisa, como o Instituto Butantã (ZICCARDI, 2009).
} 


\section{$3^{\text {o }}$ ano: Análise Matemática ( $3^{\mathrm{a}}$ parte), Geometria, História das Matemáticas ${ }^{4}$.}

É indispensável assinalar, sempre que se focaliza a instituição da subseção de Ciências Matemáticas da Faculdade de Filosofia da USP, que a estruturação de seu corpo docente se deu pela contratação de professores italianos, confiada ao matemático Theodoro Ramos ${ }^{5}$ (1895-1936). Entre eles, destaca-se a figura de Luigi Fantappiè (1901-1956), primeiro dirigente da subseção de Ciências Matemáticas, cuja atuação foi decisiva no sentido de proporcionar o desenvolvimento de atividades científicas em Matemática de modo sistemático na instituição ${ }^{6}$ (ZICCARDI, 2009). Outro docente italiano cujo nome é sempre lembrado como tendo contribuído muito para o crescimento das atividades matemáticas na Faculdade é o de Giacomo Albanese ${ }^{7}$ (1890-1947).

No dia 2 de julho de 1991, realizou-se na UNESP, Campus de Rio Claro, um seminário especial, que reuniu os professores Cândido Lima da Silva Dias (1913-1998), Benedito Castrucci (1909-1995), Edison Farah (1915-2006) e Ubiratan D’Ambrosio, sob a coordenação do professor Irineu Bicudo, para um diálogo acerca dos primeiros anos de funcionamento da subseção de Ciências Matemáticas da USP. O professor Cândido foi aluno da primeira turma do curso de Matemática e nele ingressou quando era estudante da Escola Politécnica. O professor Castrucci já entrou diretamente no curso da Faculdade de Filosofia, em 1937, assim como o professor Farah, cujo ingresso data de 1939 (GARNICA; SOUZA, 2012).

Durante o seminário, o professor Castrucci referiu-se ao fato de ter sido aluno do professor Cândido no terceiro ano, em 1939, e o professor Cândido confirmou a informação, dizendo: "Em 37, que foi o ano em que ele [Castrucci] entrou, eu já estava formado pela primeira turma da Faculdade de Filosofia, que foi a turma que terminou em 36 - 34, 35 e 36: eram três anos." (GARNICA; SOUZA, 2012, p. 185). O professor Castrucci acrescentou que

\footnotetext{
${ }^{4}$ Ziccardi (2009) afirma que não há evidências de que essa disciplina tenha sido realmente ministrada, tendo em vista que, na documentação do curso consultada em sua pesquisa de doutorado, a única referência a um conteúdo de História se localiza no programa de Análise Matemática do $1^{\circ}$ ano, de 1937, em que se lê: "Conceito de função. Evolução histórica do conceito de função".

${ }^{5}$ Theodoro Augusto Ramos, que era professor da Escola Politécnica de São Paulo, formou-se em Engenharia Civil (1917) e doutorou-se em Ciências Matemáticas (1918) pela Escola Politécnica do Rio de Janeiro. De acordo com Cavalari (2012, p. 17), Ramos "foi incumbido da importante missão de estudar o funcionamento das universidades europeias e contratar professores de alto nível científico para lecionar e formara a nova elite intelectual brasileira".

${ }^{6}$ Cavalari (2012) destaca que Fantappiè ministrou, entre cursos e disciplinas, Teoria dos Funcionais Analíticos, Teoria das Equações Diferenciais Ordinárias e Equações Derivadas Parciais, Teoria dos Números, Teoria dos Grupos de Substituição e Equações Algébricas, Funções Elíticas, Relatividade Generalizada e Grupos de Lie. Fantappiè não somente lecionou disciplinas matemáticas, mas também organizou seminários, ampliou o acervo da biblioteca, conseguiu bolsas de estudos para brasileiros na Itália e criou periódicos (ZICCARDI, 2009).

7 Segundo Cavalari (2012), Albanese responsabilizou-se por disciplinas de Geometria Diferencial e Fundamentos da Matemática.
} 
se tornou professor assistente em 1940, quando estava no último ano. Notemos que a fala do professor Cândido acentua que o curso era de três anos, enquanto a do professor Castrucci leva a crer que o seu curso foi de quatro anos, mas que, tendo feito somente os três primeiros, já lhe foi possível tornar-se professor assistente do mesmo curso em que era estudante.

O que quero ressaltar, ao citar essas recordações específicas dos professores Cândido Dias e Benedito Castrucci sobre os primeiros anos do curso de Matemática, é o fato de evidenciarem a natureza da formação provida pela Faculdade de Filosofia nesses primeiros anos, claramente distanciada da perspectiva de preparação de docentes para a escola secundária. Diversos autores (DIAS; LANDO; FREIRE, 2012; SILVA, 2002) observam que a função principal do curso era a preparação de matemáticos, ficando em segundo plano, subordinada à formação do cientista, a meta de formação profissional de professores. Para se formar como professor da escola secundária, o aluno, depois de obtido o título de bacharel nos três primeiros anos, deveria cursar um ano de Didática.

O testemunho do professor Benedito Castrucci em seu discurso de 18 de outubro de 1993, na cerimônia em que foi homenageado com o título de emérito educador, conferido pela Academia Paulista de Educação, mostra que o interesse por aspectos julgados importantes na formação do professor para a escola secundária estava ausente das concepções do professor Luigi Fantappiè, principal responsável pelo desenvolvimento inicial das atividades do curso de Matemática. Segundo Castrucci (citado por Pires, 2006, p. 215), o docente italiano, referindo-se aos cursos de Didática, disse:

A única didática que importa é o conhecimento profundo da matéria que se ensina. Um bom expositor, sem cultura, pode perder gerações ao passo que um mau didata, firme nos seus conhecimentos, beneficiará os alunos respondendo com exatidão as perguntas, seja na aula, seja fora da sala.

Dias, Lando e Freire (2012) apontam a pouca valorização do curso de Didática na Faculdade de Filosofia, Ciências e Letras da USP e informam que somente 26 dos 85 bacharéis formados por essa instituição no período que se estende de 1936 a 1952 se tornaram licenciados.

\section{De que modo a criação do primeiro curso de Matemática brasileiro deve ser} comemorada como acontecimento fundador da história da formação inicial institucional para professores?

Parece não haver dúvida de que a criação da Faculdade de Filosofia, Ciências e Letras da USP, em 1934, e da Faculdade de Filosofia da Universidade do Brasil, no Rio de Janeiro, 
em 1939, marcam inequivocamente o cenário da formação superior específica em Matemática em nosso país (SILVA, 2002; PIRES, 2006; ZICCARDI, 2009; DIAS; LANDO; FREIRE, 2012) pelo fato de nessas instituições terem se constituído os primeiros núcleos de pesquisa. Ademais, nelas teve início uma mudança em relação ao ensino da Matemática em nível superior, realizado majoritariamente em academias militares e escolas de engenharia até a década de 1930. Entretanto, no que concerne à formação de professores para o ensino secundário, fica claro, também, que essas duas instituições separaram nitidamente, desde o princípio, em seus cursos, a formação matemática da preparação pedagógica, tendo conferido à constituição de cientistas maior destaque do que à formação de docentes. Silva (2002, p. 104), em referência à Faculdade Nacional de Filosofia, chega a afirmar: "O professor secundário aparecia como um subproduto altamente especializado daquela instituição que visava, em primeiro lugar, promover a pesquisa".

Se comemorar os 80 anos do primeiro curso de Matemática do Brasil envolve vincular sua criação à formação inicial de professores em nível superior, precisamos ter em mente que estamos diante de um acontecimento ambivalente: demarca-se uma trajetória, desde 1934, na qual uma formação em Matemática num curso específico passa a se desenvolver prioritariamente na direção da pesquisa e a preparação de professores tem papel notoriamente menor.

É oportuno sublinhar que qualquer comemoração não é apenas uma rememoração de um evento do passado, digno de memória. A comemoração é um processo ativo e dirigido da memória coletiva, sempre a partir do presente, e o presente é o "lugar da construção de um certo tipo de visibilidade do passado, que ilumina alguns sentidos, congela outros, ou até mesmo recusa alguns" (CARDOSO, 1998, p. 2).

Quando pensamos na formação inicial de professores de Matemática no Ensino Superior em nosso país, um costumeiro fascínio quanto à primazia cronológica e o fato de o curso da USP ser realmente o mais antigo do Brasil podem obscurecer a existência, entre nós, de outras experiências institucionais dotadas de características diferentes, mesmo nas décadas de 1930 e 1940.

O exemplo mais eloquente é o da Universidade do Distrito Federal (UDF), que, no Rio de Janeiro, constituiu-se no primeiro espaço institucional dirigido para a formação superior de professores de todos os níveis de ensino. Anísio Teixeira, à frente da Diretoria Geral da Instrução Pública do Distrito Federal no período 1931-1935, após empreender a transformação da Escola Normal em Instituto de Educação, incorporou à UDF, criada em 1935, essa instituição. A Escola de Professores, parte do Instituto de Educação, passou a se 
chamar Escola de Educação e seu papel, além do de formar docentes para a escola primária, era o de prover a formação pedagógica dos professores secundários, que se preparariam em relação às respectivas especialidades nas outras escolas da Universidade (LOPES, 2009). No caso dos professores de Matemática, essa formação seria feita na Escola de Ciências da UDF.

O projeto de formação de professores da UDF era caracterizado, segundo Mendonça (2007), por seu caráter integrador em vários aspectos: na formação de professores primários e secundários no âmbito da universidade; na integração entre conhecimento pedagógico e disciplinar específico na preparação do professor primário, quando se buscava articular conteúdo e metodologia; na visão integrada do ensino e da pesquisa na universidade, conforme as concepções de Anísio Teixeira. Na formação dos professores para o ensino secundário, de acordo com Lopes (2009), eram previstos três anos, com um programa estruturado em cursos de conteúdo (matérias específicas do curso), cursos de fundamentos (matérias de cultura geral indispensáveis ao professor, ministradas para todas as áreas) e cursos de integração profissional (estudos de Educação propriamente ditos).

Dassie (2009) descreve as disciplinas que, em três anos, formariam os futuros docentes de Matemática, assinalando que as disciplinas educacionais já compareciam no segundo ano da formação e que o curso incluía conhecimentos histórico-filosóficos sobre a Matemática, o que revela a atribuição de importância a esses conteúdos para formar o professor. Para compreender a formação do docente em relação às questões do ensino-aprendizagem da Matemática nos cursos de integração profissional, o pesquisador valeu-se do arquivo pessoal de Euclides Roxo, professor de Prática de Ensino de Matemática na UDF. Documentos específicos referentes a essas aulas atestam que elas contemplariam exercícios de observação, de planejamento e de participação no ensino desenvolvido em classes da Escola Secundária regidas pelo próprio professor de Prática (DASSIE, 2009). Torna-se claro que a formação docente desenvolvida na UDF envolvia a articulação direta com o ensino secundário mediante as interações dos estudantes com a Escola Secundária da mesma universidade.

Contudo, essa experiência teve caráter efêmero: a UDF foi extinta e seus cursos foram transferidos para a Universidade do Brasil em janeiro de 1939; em abril do mesmo ano, organizou-se a Faculdade Nacional de Filosofia (FNFi), anteriormente mencionada neste texto, a partir da já existente Faculdade de Filosofia, Ciências e Letras do Rio de Janeiro. Os currículos e programas da Faculdade Nacional de Filosofia serviram para configurar todos os cursos de formação de professores nas faculdades de filosofia oficialmente reconhecidas no país desde 1939, caracterizados por sua composição em duas partes diferenciadas: a primeira, feita de disciplinas científicas, era suficiente para a obtenção do título de bacharel; a segunda, 
a do curso de didática, somada à primeira, constituía a formação do licenciado nas diversas áreas (DIAS; LANDO; FREIRE, 2012). É esse, como se sabe, o célebre modelo “3+1”.

Para a formação de professores de Matemática, concentravam-se disciplinas de Matemática e Física ${ }^{8}$ nos três primeiros anos do curso que formava o bacharel, ficando as disciplinas pedagógicas (Didática Geral, Didática Especial, Psicologia Educacional, Administração Escolar, Fundamentos Biológicos da Educação e Fundamentos Sociológicos da Educação) alocadas exclusivamente no último ano (DASSIE, 2008).

No entanto, mesmo nesse modelo, parece ter havido diferenças sensíveis no que concerne ao interesse dos estudantes, conforme o ambiente em que o curso era desenvolvido. Destacamos o caso da Bahia, estudado por Dias, Lando e Freire (2012). Na capital desse estado, a Faculdade de Filosofia foi fundada três anos depois da FNFi, em 1942, e, de maneira distinta do que ocorreu em São Paulo e no Rio de Janeiro, em que se contrataram especialistas estrangeiros para fomentar a formação de cientistas, seu corpo de catedráticos se constituiu de intelectuais locais, médicos, engenheiros, advogados e religiosos, que já atuavam no ensino secundário e superior em Salvador. Em particular, os catedráticos de Matemática eram engenheiros que lecionavam na Escola Politécnica. Dezessete dos 18 bacharéis formados pela instituição de 1945 a 1952 se graduaram também na licenciatura, o que representa um percentual bastante superior ao dos concluintes da licenciatura na USP no mesmo período 9 .

Como tem sido divulgado em vários estudos, a proposta da $\mathrm{FNFi}$, praticamente a mesma da USP, orientou a implementação de cursos de Matemática, a partir de 1939, em diversas cidades, em instituições públicas e privadas. Por exemplo, Ferreira (2012, p. 102), que pesquisou a primeira licenciatura mineira em Matemática, a da Faculdade de Filosofia, Ciências e Letras de Minas Gerais, curso criado em 1939, apresenta em seu trabalho a estrutura desse curso, que reproduz sem qualquer alteração a do curso da Faculdade Nacional de Filosofia.

Entre as investigações recentes sobre as licenciaturas em Matemática que surgiram no Brasil desde o aparecimento do curso da USP, destaca-se a realizada por Martins-Salandim (2012) sobre o estado de São Paulo. A autora verificou que, até o final de 1950, havia

\footnotetext{
${ }^{8}$ Primeiro ano: Análise Matemática, Geometria Analítica e Projetiva, Física Geral e Experimental; segundo ano: Análise Matemática, Geometria Descritiva e Complementos de Geometria, Mecânica Racional, Física Geral e Experimental; terceiro ano: Análise Superior, Geometria Superior, Física Matemática, Mecânica Celeste.

${ }^{9}$ Depois de 1952, quando a licenciatura passou a ser concluída antes do bacharelado, entre os 101 graduados em Matemática, cem se licenciaram e apenas 38 se graduaram como bacharéis. A partir de 1946, a formação do quarto ano de licenciatura, além das disciplinas regulares do curso de didática, passou a incluir componentes didáticos de cunho teórico e prático na escola de aplicação anexa à Faculdade de Filosofia. Dois nomes se sobressaem no cenário baiano: Isaías Alves de Almeida (1888-1968) e Anísio Teixeira (1900-1971) (DIAS; LANDO; FREIRE, 2012).
} 
somente cinco desses cursos, enquanto na década de 1960 principia um movimento de expansão, com a instalação de oito deles em cidades do interior, além de mais um na capital. Martins-Salandim buscou compreender esse movimento específico dos anos 1960, estudando a criação, a instalação e o desenvolvimento inicial desses cursos instalados nos municípios de Araraquara, Campinas, Dracena, Presidente Prudente, Santo André, São José do Rio Preto, São Paulo, Taubaté e Tupã, em instituições públicas e particulares. Ao terminar seu trabalho, a autora afirmou que

\begin{abstract}
Por um lado, aqueles cursos de Matemática criados inicialmente no formato de licenciatura buscavam aproximar-se mais de uma estrutura, próxima ao bacharelado, que refletia o modelo pré-existente da USP-São Paulo e atendia aos anseios de titulação de muitos professores que viam a formação pós-graduada como eixo central da carreira docente em nível superior, numa posição que se alia e é reforçada pela estruturação, à época, dos Programas de Pós-Graduação em Matemática no Brasil. Por outro lado, estes mesmos cursos rendiam-se à exigência legal de manter e colocar em atuação profissionais com formação universitária. [...] Este movimento que examinamos revela-nos que, em relação aos cursos de Matemática, não havia uma intenção clara de formar os professores que atuariam no ensino secundário, também ele em fase de expansão na década de 1960 (MARTINS-SALANDIM, 2012, p. 347).
\end{abstract}

Martins-Salandim conclui que a maioria dos cursos que pesquisou não assumiu efetivamente a função de formação profissional do professor e que não se constituiu, portanto, com eles, um espaço específico para essa formação.

Para finalizar esta parte, é importante enfatizar, no ensejo dos 80 anos do primeiro curso de Matemática do Brasil, a necessidade de ir além da leitura das origens dos atuais processos de formação de professores nesse curso ou no da FNFi. Se esse quadro centralizador não pode ser negligenciado ou desprezado, deve ser relativizado à luz de investigações mais recentes, que evidenciam, ao lado da variedade de instâncias formadoras e da diversidade dos agentes sociais que exercem ou exerceram a docência em Matemática no que se denomina hoje Educação Básica, a impossibilidade de se atribuir a esses sujeitos uma identidade estável ou fixa (GARNICA, 2014).

\title{
4 Oitenta anos depois da criação do primeiro curso de Matemática no Brasil: algumas questões do presente na formação inicial de professores de Matemática
}

Conceitualmente falando, o curso de Licenciatura atual ainda é muito parecido com o primeiro curso de Matemática, criado na Universidade de São Paulo (USP), em 1934. Na maioria das instituições, as disciplinas ainda são agrupadas em conteúdo específico e conteúdos pedagógicos, com tendência a valorizar mais o primeiro grupo que o segundo, mesmo em se tratando da formação do professor de Matemática e não do bacharel em Matemática (SBEM, 2013, p. 3-4). 
Não existe um verdadeiro ato de memória que não esteja ancorado nos desafios identitários presentes (CANDAU, 2014, p. 150).

Oitenta anos depois do estabelecimento do curso de Matemática da USP, mudou radicalmente o quadro da Educação brasileira e cresceu imensuravelmente a pesquisa educacional, o que evidentemente repercute com muita força nas concepções sobre a preparação de professores. A formação de professores para ensinar Matemática (usando essa expressão para incluir os docentes dos Anos Iniciais da escolarização) é tema de um número enorme de investigações e foco de inúmeros eventos e publicações.

Mudou significativamente desde o início dos anos 2000 a normatização relativa à Educação em seus diversos aspectos, incluindo-se, entre eles, os cursos de licenciatura. É fundamental considerar que, ainda que possa ser grande a distância entre os registros formais dos documentos e a realidade concreta, as diretrizes vigentes na atualidade trouxeram importantes inovações para a formação de professores, entre as quais se sobressaem o caráter democrático de sua elaboração; o reconhecimento da docência como profissão, mais do que a posse de um dom ou vocação; a autonomia do percurso de formação docente, com a exigência de um projeto pedagógico específico para o curso, buscando a superação de sua visão como apêndice do bacharelado; a nova concepção de Educação Básica; a ampliação da dimensão prática da formação; a ideia de que há competências específicas a serem adquiridas para a docência, vencendo-se a improvisação e o amadorismo (SOUZA, 2014). Todavia, se é impossível desconhecer a presença de avanços em consonância com o conjunto das transformações da realidade brasileira, não se pode negar que a realidade da educação escolar está muito distante dos ideais que nutriram as lutas pelas mudanças realizadas e que o quadro geral do exercício da profissão de professor, hoje, tem como característica marcante a precariedade da condição docente - "o estado real que determina, na ordem econômica, social, política, cultural e ideológica os modos como a prática pedagógica é realizada" (SOUZA, 2014, p. 43). Estão colocados, portanto, inúmeros desafios para a formação docente.

No caso da licenciatura em Matemática, a epígrafe desta seção, extraída do documento produzido pela comissão paritária SBEM/SBM publicado em 2013, ao considerar que a formação inicial de professores de Matemática, na atualidade, conceitualmente ainda é próxima daquela que foi proposta oitenta anos atrás, deixa claro "que não se mudam práticas cristalizadas no tempo apenas com pareceres e resoluções e que os fatores internos às universidades não podem ser lidos fora do contexto social no qual cada uma delas está inserida" (ARANHA; SOUZA, 2013, p. 81). Se hoje não se pode mais dizer que a 
organização curricular dos cursos de licenciatura em Matemática se configura literalmente como " $3+1$ ", com três quartos da carga de disciplinas ocupados pelos conteúdos matemáticos e físicos, como nos cursos surgidos a partir da década de 1930 espelhados no modelo da USP e da FNFi, "a lógica subjacente ao 3+1 ainda permanece como a lógica estruturante desses $\operatorname{cursos}^{10,}$ (MOREIRA, 2012, p. 140).

Sabemos que, nas práticas cotidianas de muitos professores formadores que atuam nas licenciaturas em Matemática, o essencial da formação é o domínio dos conteúdos da Matemática acadêmica, mesmo sem uma explicitação mais precisa de seu papel ou quaisquer questionamentos acerca de sua contribuição para a prática pedagógica na Educação Básica. É interessante, nesse contexto, lembrar a situação explanada por Silva (2013) quanto ao curso de licenciatura em Matemática da Universidade Estadual Paulista (UNESP), campus de Rio Claro. O curso de Matemática oferecido pela instituição "é (re)conhecido por suas iniciativas em relação a questões relativas ao ensino da Matemática e pelo importante papel que representou para o movimento da Educação Matemática no Brasil” (SILVA, 2013, p. 274); ademais, foi na UNESP-Rio Claro que teve início o primeiro curso de mestrado em Educação Matemática do país. Entretanto, o exemplo de Heloisa da Silva, concernente à disciplina Fundamentos da Matemática Elementar, do curso de licenciatura, evidencia dificuldades verificadas nas práticas de formação docente da mesma natureza das que comentamos. A disciplina citada pela autora tem como um de seus objetivos relacionar os conteúdos matemáticos ministrados nos Ensinos Fundamental e Médio aos temas estudados nas diversas disciplinas da licenciatura; contudo, esse objetivo não é necessariamente contemplado, dependendo primordialmente do professor que ministrar a disciplina. Mais: ele pode nem sequer "fazer sentido para um matemático que entende que para ensinar um conteúdo basta conhecê-lo" (SILVA, 2013, p. 275).

Exemplos como esse, que, aliás, são comuns, como é sabido, em outros cursos de licenciatura em Matemática, nos impelem a concordar com Moreira (2012) quanto à necessidade urgente de estudos e pesquisas que situem melhor o papel e a eventual contribuição da matemática acadêmica para a matemática do professor.

Além disso, os argumentos mais recentemente desenvolvidos sobre a necessidade de uma formação matemática na licenciatura que contemple diretamente o trabalho docente escolar, levando “em consideração as características e os objetivos da prática para a qual se

\footnotetext{
${ }^{10}$ Moreira (2012), tendo examinado as matrizes curriculares de licenciaturas de algumas grandes universidades brasileiras, avaliou que os chamados conteúdos científicos (Matemática, Física, Computação e Estatística) perfazem, nesses cursos, de 45 a 55 por cento do tempo da formação acadêmica inicial.
} 
destina o profissional a ser formado" (SBEM, 2013, p. 5), não atingiram ainda a formulação de propostas específicas que possam contemplar a almejada formação matemática do licenciando. O próprio documento produzido pela comissão paritária SBEM/SBM, embora em diversos momentos afirme que a formação matemática sintonizada com as questões da prática docente é um parâmetro essencial a ser observado na formação do licenciado em Matemática, ao apresentar-se de maneira muito genérica em relação a tal aspecto, pende acentuadamente para o lado do tratamento dos conteúdos do ponto de vista da Matemática acadêmica. Estes são abordados de forma muito minuciosa, "a partir de uma visão que privilegia os valores próprios do conhecimento matemático acadêmico, enquanto, em momento algum, se analisam criticamente esses valores a partir das necessidades concretas da prática docente escolar" (FERREIRA, 2014, p. 155). Mesmo percebendo que a constituição de um corpo de conhecimentos matemáticos específicos para o ensino escolar ainda está em processo de construção, torna-se visível que um dos maiores desafios quanto à formação do professor é o "de construir um currículo de licenciatura em matemática que tenha como fundamento as pesquisas consolidadas sobre os saberes (e a necessidade de saberes) da prática docente escolar em matemática" (Idem, ibidem).

Outras questões poderiam ser abordadas em relação à formação inicial do professor de Matemática, tomando como ponto de partida a comemoração dos 80 anos do primeiro curso de Matemática brasileiro. Tratamos apenas de algumas delas, por acreditar que um ato comemorativo pode converter a lembrança do passado em um questionamento crítico do presente.

\section{Referências}

ARANHA, A. V. S.; SOUZA, J. V. A. de. As licenciaturas na atualidade: nova crise? Educar em Revista, Curitiba, n. 50, p. 69-86, 2013.

CACETE, N. H. Breve história do ensino superior brasileiro e da formação de professores para a escola secundária. Educação e Pesquisa, São Paulo, v. 40, n. 4, p. 1061-1076, 2014.

CANDAU, J. Memória e identidade. Tradução de Maria Letícia Ferreira. São Paulo: Contexto, 2014.

CARDOSO, I. de A. R. A universidade da comunhão paulista: o projeto de criação da Universidade de São Paulo. São Paulo: Autores Associados/Cortez, 1982.

CARDOSO, I. 68: a comemoração impossível. Tempo Social. Rev. Sociol. USP, São Paulo, 10 (2), p. 1-12, out. 1998. 
CAVALARI, M. F. Um histórico do curso de Matemática da Faculdade de Filosofia, Ciências e Letras (FFCL) da Universidade de São Paulo (USP). Revista Brasileira de História da Matemática, Rio Claro, v. 12, n. 25, p. 15-30, 2012.

DASSIE, B. A. A contribuição de Euclides Roxo para a formação do professor de Matemática na UDF. In: FÁVERO, M. L. de A.; LOPES, S. de C. (Org.). A Universidade do Distrito Federal (1935-1939): um projeto além de seu tempo. Brasília: Liber Livro, 2009, p. 99-128.

DASSIE, B. A. A formação de professores no Rio de Janeiro na primeira metade do século XX. In: COLÓQUIO DE HISTÓRIA E TECNOLOGIA NO ENSINO DA MATEMÁTICA, 4., 2008, Rio de Janeiro. Anais.... Rio de Janeiro: LIMC, 2008, p. 1-8. Disponível em: < https://sistemas.uff.br/jspui/bitstream/1/337/1/HTEM4_2008_DASSIE.pdf $>$. Acesso em: $08 \mathrm{dez}$. 2014.

DIAS, A. L. M.; LANDO, J. C.; FREIRE, I. A. Formação de professores na Bahia: os cursos de Matemática e de Didática da Faculdade de Filosofia (1943-1968). In: FERREIRA, A. C.; BRITO, A. J.; MIORIM, M. A. Histórias de formação de professores que ensinaram Matemática no Brasil. Campinas: Ílion, 2012, p. 115-135.

FERREIRA, A. C. A Faculdade de Filosofia, Ciências e Letras de Minas Gerais e a primeira licenciatura em Matemática do estado. In: FERREIRA, A. C.; BRITO, A. J.; MIORIM, M. A. Histórias de formação de professores que ensinaram Matemática no Brasil. Campinas: Ílion, 2012, p. 93-114.

FERREIRA, M. C. C. Conhecimento matemático específico para o ensino na educação básica: a álgebra na escola e na formação do professor. 2014. 184f. Tese (Doutorado em Educação). Faculdade de Educação, Universidade Federal de Minas Gerais, Belo Horizonte, 2014.

GARNICA, A. V. M. Cartografias contemporâneas: mapear a formação de professores de Matemática. In: GARNICA, A. V. M. (Org.). Cartografias contemporâneas: mapeando a formação de professores de Matemática no Brasil. Curitiba: Appris, 2014.

GARNICA, A. V. M.; SOUZA, L. A. Elementos de História da Educação Matemática. São Paulo: Cultura Acadêmica/ Editora Unesp, 2012.

LOPES, S. de C. A Escola de Educação como eixo integrador da Universidade. In: FÁVERO, M. L. de A.; LOPES, S. de C. (Org.). A Universidade do Distrito Federal (1935-1939): um projeto além de seu tempo. Brasília: Liber Livro, 2009, p. 45-67.

MARTINS-SALANDIM, M. E. A interiorização dos cursos de Matemática no estado de São Paulo: um exame da década de 1960. 2012. 379 f. Tese (Doutorado em Educação Matemática). Instituto de Geociências e Ciências Exatas, Universidade Estadual Paulista, Rio Claro, 2012.

MENDONÇA, A. W. P. C. Uma profissão fragmentada. In: NEPOMUCENO, M. de A.; TIBALLI, E. F. A (Org.). A educação e seus sujeitos na história. Belo Horizonte: Argvmentvm, 2007, p. 35-64.

MOREIRA, P. C. $3+1$ e suas (In)variantes (Reflexões sobre as possibilidades de uma nova estrutura curricular na Licenciatura em Matemática). Bolema, Rio Claro, v. 26, n. 44, p. 1137-1150, 2012.

PENIN, S. T. de S. A formação de professores e a responsabilidade das universidades. Estudos Avançados, São Paulo, v. 15, n. 42, p. 317-332, 2001.

PIRES, R. da C. A presença de Nicolas Bourbaki na Universidade de São Paulo. Tese (Doutorado em Educação). 2006. 578f. Pontifícia Universidade Católica de São Paulo, São Paulo, 2006. 
SBEM. A formação do professor de matemática no curso de licenciatura: reflexões produzidas pela comissão paritária SBEM/SBM. Brasília: Sociedade Brasileira de Educação Matemática, Boletim SBEM, n. 21, p. 1-42, fev.2013.

SILVA, C. M. S. da. Formação de professores e pesquisadores de Matemática na Faculdade Nacional de Filosofia. Cadernos de Pesquisa, São Paulo, n. 117, p. 103-126, 2002.

SILVA, H. da. Integrando história oral e narrativas a abordagens pedagógicas problematizadoras na formação inicial de professores de matemática. Revista Educação PUC-Campinas, Campinas, v. 18, n. 3, p. 269-285, 2013.

SOUZA, J. V. A. de. Dimensão normativa e desafios atuais dos cursos de licenciatura. In: SOUZA, J. V. de A.; DINIZ, M.; OLIVEIRA, M. G. de. Formação de professores (as) e condição docente. Belo Horizonte: Editora UFMG, 2014, p. 27-56.

ZICCARDI, L. R. N. O curso de Matemática da Pontifícia Universidade Católica de São Paulo: uma história de sua construção/desenvolvimento/legitimação. 2009. 408f. Tese (Doutorado em Educação Matemática). Pontifícia Universidade Católica de São Paulo, São Paulo, 2009.

Submetido em Maio de 2015. Aprovado em Junho de 2015. 